\title{
Analysis of Lingual Arch Form in Dental Students of Nepal with Normal Occlusion
}

This article was published in the following Dove Press journal:

Clinical, Cosmetic and Investigational Dentistry

\author{
Dashrath Kafle (iD ${ }^{\prime}$ \\ Vasant Devagiri ${ }^{2}$ \\ Prabhat Kumar Chaudhari (iD) ${ }^{3}$ \\ Rajeev Kumar Mishra' \\ 'Department of Orthodontics, \\ Kathmandu University School of Medical \\ Sciences, Dhulikhel, Bagmati, Nepal; \\ ${ }^{2}$ Department of Orthodontics, College of \\ Medical Sciences, Kathmandu University, \\ Bharatpur, Bagmati, Nepal; ${ }^{3}$ Division of \\ Orthodontics and Dentofacial \\ Deformities, All India Institute of Medical \\ Sciences, New Delhi, Delhi, India
}

Correspondence: Rajeev Kumar Mishra Kathmandu University School Of Medical Sciences, Dhulikhel, Bagmati, Nepal Tel +977-98I7852I66

Email mishra.rkm84@gmail.com

\begin{abstract}
Background: The objectives of this study were to describe and classify lingual arch form in dental students with normal occlusion and explore the possibility to provide a lingual arch form template for Nepalese population.

Methods: The occlusion and arch form of 220 undergraduate dental students were analyzed and thirty-three subjects (14 males, 19 females) fulfilling the inclusion criteria were selected for the study. Reference points were drawn on the lingual surfaces of the teeth of study model using an indelible marker. A transparent ruled grid was used to obtain $\mathrm{x}$ and $\mathrm{y}$ coordinate values of the reference point. Following distances were measured with a digital caliper: intercanine width, inter-molar width, inter-second molar width, canine depth, first molar depth, and second molar depth. Two-step cluster analysis was used to further classify the arch. The mean reference point values of each cluster were entered into the software (CurveExpert 1.4, Hymas developers). The curve finder tool of the software was used to obtain the curve which best described the arch forms.

Results: Two-step cluster analysis identified two distinguished clusters of lingual arch forms. Tenth degree polynomial was chosen as the best possible fit for lingual arch forms by using Curvefinder tool of the software CurveExpert 1.4.

Conclusion: Two types of anatomical lingual arch forms derived from Nepalese dental students with normal occlusion have been described and templates for the same have been generated.
\end{abstract}

Keywords: lingual arch form, lingual orthodontics, cluster analysis, normal occlusion, polynomial

\section{Background}

The human dental arch form has been studied extensively because of its importance in orthodontic treatment planning and retention. ${ }^{1}$ Preservation of pretreatment arch shape and dimensions, particularly of the mandibular arch, is considered a key factor for stability of the post-treatment occlusion. ${ }^{2}$ The human dental arch form has been described as geometrical shapes like ellipse, parabola, hyperbola and has also been classified using curves obtained using various mathematical equations like polynomial equations, cubic spline function, Euclidian distance matrix analysis, Fourier series, etc. ${ }^{3}$ However, very few studies have been done about arch form from the lingual/palatal perspective. ${ }^{4-6}$ The number of patients undergoing lingual

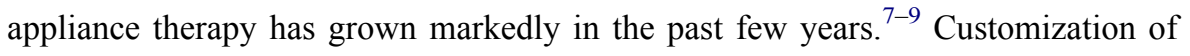
arch wires to match the patient's arch form is an important step in labial as well as lingual orthodontics. ${ }^{4}$ The mushroom-shaped arch form has been commonly used in lingual orthodontics. However, the mushroom-shaped arch form has several 
challenges including the need for complex wire bending, difficult upper and lower arch co-ordination, and complex treatment mechanics. Utilizing a lingual straight wire technique may simplify mechanics, reduces chair time, and potentially improves patient comfort. ${ }^{10,11}$

The effect of ethnicity on labial arch form is well documented. ${ }^{12}$ Hence, it will be logical to assume that similar variations exist for the lingual arch form. The lingual arch form in the Caucasian ${ }^{4,5}$ and Korean population ${ }^{6}$ has been analyzed; however, no such studies have been conducted for Nepalese population samples.

The aim of the study was to describe and classify lingual arch forms in Nepalese dental subjects with normal occlusions which could also possibly be used as a setup guide for lingual orthodontic treatment in the general Nepalese population.

\section{Methods}

The study models of thirty-three subjects (19 females, 14 males) with normal occlusion were retrieved for this study from the archives of Orthodontics Department of College of Medical Sciences, Bharatpur, Nepal. The subjects included in this study had been selected based on following inclusion criteria: bilateral Angle's class I molar and canine relationships, fully erupted dentition upto the permanent second molars, regular arch form with minimal $(\leq 3 \mathrm{~mm})$ or no crowding, normal overjet and overbite $(2 \mathrm{~mm} \pm 1 \mathrm{~mm})$, minimal $(\leq 2 \mathrm{~mm})$ or no spacing, and the absence of large lingual/palatal restorations. The median axis of the clinical crown on the lingual side was traced with a pencil. Occlusal, middle and gingival thirds of the crown were marked by drawing two horizontal reference lines with a pencil. The reference points for this study were drawn as described by Lombardo et al. ${ }^{4}$ The reference points were marked with an OHP marker (Snowman OPM,1.0 mm) (Figure 1) in the maxillary and mandibular arch. For the maxillary anterior teeth, the reference points were marked at the junction of the middle third and the gingival third and for the mandibular anterior teeth in the middle third of the clinical crown along their central lingual axes. In maxillary posterior teeth reference points were marked at the center of the clinical crown. In the mandibular arch, reference points were marked at the center of the clinical crown (vertical position) along the central lingual axis and at the most prominent point on the lingual surface of each tooth (horizontal position) on the molars and premolars. These reference points provide a direct clinical representation of the lingual side of the arch. ${ }^{4}$ Seven reference points were made on each quadrant, from central incisor to 2nd molar. A millimeter graph was printed on lamination paper and mounted on a transparent plastic sheet of $1.5 \mathrm{~mm}$ thickness. This sheet was placed over the study cast so that the posterior border of study model was aligned along the abscissa and the median line with the ordinate, thus creating a Cartesian coordinate system (Figure 1). A Cartesian coordinate system can be used in two-dimensional planes or three-dimensional spaces. For two-dimensional planes, the system consists of two perpendicular lines ( $\mathrm{x}$-axis and $\mathrm{y}$-axis) which intersect at a point called the origin. The location of any particular point is given by coordinates which represent its distance from the $\mathrm{x}$ and $\mathrm{y}$ axes. ${ }^{14}$ The Cartesian

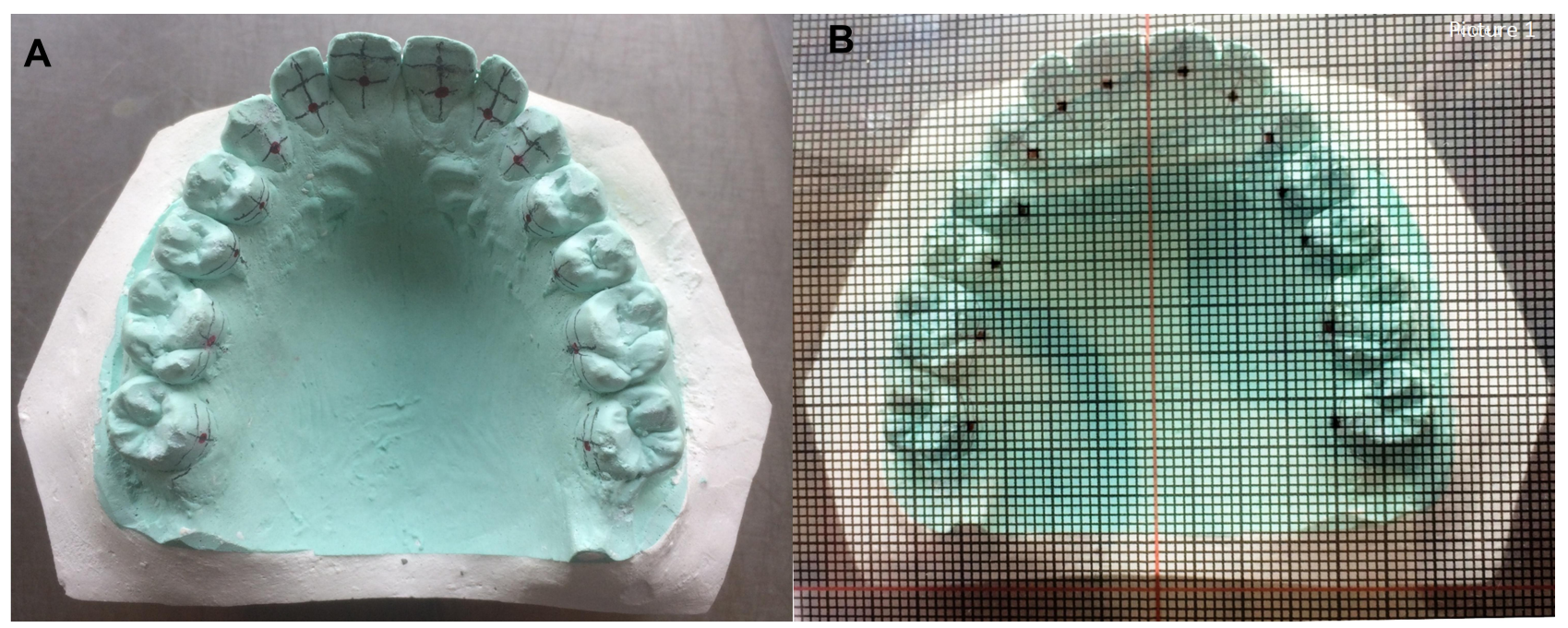

Figure I (A) Marking of reference points. (B) Measurement of $x$ and $y$ co-ordinates. 
coordinates $(\mathrm{x}, \mathrm{y})$ of each reference point were calculated; $\mathrm{X}$ measurements, the distance between the reference point, and the y-axis; y measurements, the distance between the reference point and the $\mathrm{x}$-axis. To compensate for the minor asymmetries in the left and right side of the arches, method similar to that described by Trivino et al was used. $^{15}$ The reference point coordinates of the 33 dental casts were divided into the left and right quadrants. Each quadrant was described by seven reference points $(7 \mathrm{x}$ and y coordinates), and was then "mirrored" to obtain 66 complete maxillary and 66 complete mandibular arches with symmetrical curves. ${ }^{7}$ The mean $x$ and $y$ value of each fourteen reference point were calculated and processed using CurveExpert software (version 1.4, https:// www.curveexpert.net/products/curveexpert-basic/,Hyams

Development). The Curve finder tool of the software was used to find the curve which best described the lingual dental arch forms.

Following measurements were done on the mandibular cast with a digital caliper (Figure 2): 1) inter-canine width, 2) inter-first molar width, 3. inter-second molar width, 4) canine depth: the distance between the inter-incisor point and the line connecting the canine reference points, 5) first molar depth: the distance between the inter-incisor point and the line connecting the reference points on the first molars and 6) second molar depth: the distance between the inter-incisor point and the line connecting the reference points on the second molars. Three ratios were calculated: 1) canine width/depth, 2) first molar width/depth and 3) second molar width/depth. Statistical analysis was performed using SPSS software (version 20)
Descriptive statistical analysis was used to obtain mean and standard deviation. Shapiro-Wilk test was used to test the normalcy of the lingual measurements. To identify sexual dimorphism independent $t$-test was used in measurements with the normal distribution. To test the reliability of the measurements, $x$ and $y$ coordinates of left central incisors, canines, second premolars and second molars of maxillary and mandibular arches were re-evaluated in fifteen pairs of casts. Paired $t$-test was used to calculate the systematic error and Dahlberg's formula ${ }^{16}$ was used to measure the casual error. Two-step cluster analysis was used to classify the arches into clusters. Two-step cluster analysis was done using the following variables for cluster identification: a) inter-canine width, b) inter-molar width, c) 2nd molar width, d) canine depth, e) first molar depth, f) second molar depth, g) canine width/ depth, h) first molar width/depth and i) second molar width/depth. The Two-step Cluster Analysis procedure is an exploratory tool designed to reveal natural groupings (or clusters) within a dataset that would otherwise not be apparent. $^{17}$ The auto clustering feature automatically determined the "best" number of clusters by using the criterion specified in the Clustering Criterion group. ${ }^{17}$ The mean $\mathrm{x}$ and $\mathrm{y}$ coordinate data of each reference for both clusters were plotted in CurveExpert software, and the software's Curvefinder tool was used to find the best fitting curve.

\section{Results}

Shapiro-Wilk test showed that the data had a normal distribution. Independent $t$-test showed that there was no significant difference between male and female subjects in

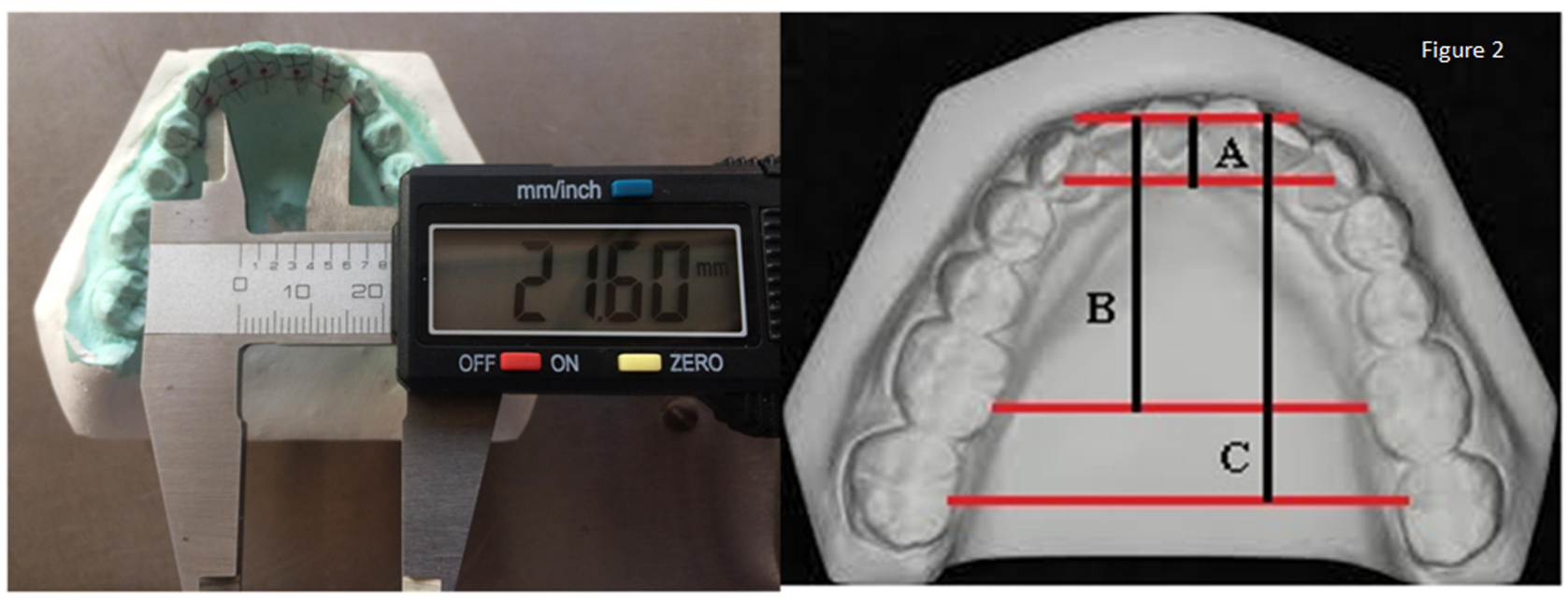

Figure 2 Measurement of lingual arch dimensions. (A) Canine depth. (B) First molar depth. (C) Second molar depth. 
Table I Comparison Between Lingual Measurements of Males and Females

\begin{tabular}{|c|c|c|c|}
\hline $\begin{array}{l}\text { Lingual } \\
\text { Measurements }\end{array}$ & $\begin{array}{l}\text { Male } \\
\text { (Mean士 } \\
\text { S.D) }\end{array}$ & $\begin{array}{l}\text { Female } \\
\text { (Mean士 } \\
\text { S.D) }\end{array}$ & p-value \\
\hline Inter-canine width & $22.47 \pm 1.44$ & $22.34 \pm 1.28$ & $0.78(N S)$ \\
\hline Inter-molar width & $34.35 \pm 2.81$ & $33.71 \pm 1.92$ & $0.82(N S)$ \\
\hline Inter-2nd molar width & $40.88 \pm 3.05$ & $40.33 \pm 2.22$ & $0.91(N S)$ \\
\hline Canine depth & $4.35 \pm 1.13$ & $4.61 \pm 0.96$ & $0.47(N S)$ \\
\hline First molar depth & $24.87 \pm 1.42$ & $25.76 \pm 1.32$ & $0.07(\mathrm{NS})$ \\
\hline Second molar depth & $34.13 \pm 1.73$ & $35.23 \pm 1.69$ & $0.07(\mathrm{NS})$ \\
\hline Canine width/depth & $5.59 \pm 1.89$ & $5.03 \pm 1.02$ & $0.37(\mathrm{NS})$ \\
\hline First molar width/depth & $1.35 \pm 0.17$ & $|.3| \pm 0.1$ & $0.37(\mathrm{NS})$ \\
\hline $\begin{array}{l}\text { Second molar width/ } \\
\text { depth }\end{array}$ & $1.2 \pm 0.08$ & $1.15 \pm 0.07$ & 0.06 (NS) \\
\hline
\end{tabular}

Note: $\mathrm{P} \leq 0.05$

Abbreviation: NS, not significant.

regard to arch dimensions (Table 1, p-value: 0.06-0.91). Paired $t$-test and Dahlberg's formula showed high reliability of co-ordinate measurement (Table 2). The two-step Cluster analysis yielded two distinct clusters (Table 3). The cluster properties are presented in Table 4. The two clusters showed significant differences between intercanine width $(\mathrm{p}=0.00)$ inter-1 stmolar width $(\mathrm{p}=0.00)$ and inter-2nd molar width $(\mathrm{p}=0.00)$. Similarly, significant differences were also observed for 1 st molar width/depth

Table 2 Evaluation of Reliability of Measurement with Paired $t$-Test and Dahlberg's Formula

\begin{tabular}{|l|l|l|l|l|}
\hline Tooth & $\begin{array}{l}\text { Measurement } \\
\text { I (Mean } \pm \text { S. } \\
\text { D.) }\end{array}$ & $\begin{array}{l}\text { Measurement } \\
\text { 2 (Mean } \pm \text { S. } \\
\text { D) }\end{array}$ & p-value & $\begin{array}{l}\text { Casual } \\
\text { Error }\end{array}$ \\
\hline $21 x$ & $4.13 \pm 0.35$ & $3.93 \pm 0.45$ & $0.18(\mathrm{NS})$ & 0.31 \\
$23 x$ & $13.93 \pm 0.7$ & $13.7 \pm 1.1$ & $0.33(\mathrm{NS})$ & 0.36 \\
$25 x$ & $16.8 \pm 1.2$ & $16.5 \pm 1.2$ & $0.33(\mathrm{NS})$ & 0.36 \\
$27 x$ & $21.2 \pm 2.0$ & $21.4 \pm 2.2$ & $0.30(\mathrm{NS})$ & 0.36 \\
$31 x$ & $-2.73 \pm 0.45$ & $-2.87 \pm 0.58$ & $0.43(\mathrm{NS})$ & 0.25 \\
$33 x$ & $-11.13 \pm 1.0$ & $-10.93 \pm 0.96$ & $0.18(\mathrm{NS})$ & 0.31 \\
$35 x$ & $-14.73 \pm 1.5$ & $-14.47 \pm 1.12$ & $0.49(\mathrm{NS})$ & 0.36 \\
$37 x$ & $-20.13 \pm 1.9$ & $-20.53 \pm 2.8$ & $0.58(\mathrm{NS})$ & 0.44 \\
$21 y$ & $56.0 \pm 2.6$ & $55.0 \pm 2.2$ & $0.61(\mathrm{NS})$ & 0.31 \\
$23 y$ & $49.27 \pm 2.5$ & $49.0 \pm 2.44$ & $0.48(\mathrm{NS})$ & 0.36 \\
$25 y$ & $36.67 \pm 2.8$ & $36.33 \pm 2.5$ & $0.38(\mathrm{NS})$ & 0.40 \\
$27 y$ & $19.2 \pm 3.0$ & $19.2 \pm 2.4$ & $1.00(\mathrm{NS})$ & 0.00 \\
$31 y$ & $55.4 \pm 2.6$ & $55.27 \pm 2.7$ & $0.82(\mathrm{NS})$ & 0.25 \\
$33 y$ & $51.0 \pm 2.9$ & $50.6 \pm 2.8$ & $0.53(\mathrm{NS})$ & 0.44 \\
$35 y$ & $39.0 \pm 3.4$ & $38.6 \pm 2.9$ & $0.67(\mathrm{NS})$ & 0.40 \\
$37 y$ & $21.07 \pm 3.1$ & $20.47 \pm 3.4$ & $0.50(\mathrm{NS})$ & 0.31 \\
\hline
\end{tabular}

Note: $\mathrm{P} \leq 0.05$.

Abbreviation: NS, not significant.
Table 3 Cluster Distribution

\begin{tabular}{|l|l|l|}
\hline Cluster & Number of Subjects & \% of Total \\
\hline I & 20 & 60.6 \\
2 & 13 & 39.4 \\
\hline
\end{tabular}

ratio $(\mathrm{p}=0.00)$ and 2 nd molar width/depth ratio $(\mathrm{p}=0.01)$. The tenth degree polynomial was chosen as best possible fit for these arch forms by using Curvefinder tool of the software CurveExpert 1.4 (Figures 3 and 4).

\section{Discussions}

To a large extent, the success of straight wire orthodontic treatment depends on the selection of archwires irrespective of the surface used to bond attachments. Archwires made of superelastic materials, which cannot be customized, should be selected on the basis of dimensional similarity, types of malocclusion, and ethnicity. ${ }^{4}$ Labial arch forms have been described in numerous studies, but very few studies have been reported regarding lingual arch form. The purpose of this study was to develop a template which can be used for straight wire lingual orthodontics, especially for the Nepalese population. All the subjects were adult or near the end of growth, hence we expect a minimal effect of growth-related changes in the arch form. Previous studies have used scanned images of study models alone for establishing the Cartesian system. ${ }^{4,6}$ In our study, we have used a modified millimeter sheet to directly establish the Cartesian system and to obtain the $\mathrm{x}$ and $\mathrm{y}$ coordinates of the reference points. This may have been a source of error as the cast or measuring sheet could move during the measurement. However, all the readings were recorded by a single observer and statistical tests showed a high reliability of measurement (casual error range 0.00 0.44). To prevent eye fatigue, all the recordings were done in the first working hour of the day. The readings of only two casts were obtained each day.

The Curvefinder tool of CurveExpert software has been reliably used for generating the best-fit curve for the arch forms in similar previous studies. ${ }^{4,15}$ Polynomial equation has been commonly used to describe the dental arch forms. ${ }^{18-22}$ In the literature, various degree of polynomials have been used to describe the arch forms. Ferrario et $\mathrm{al}^{21}$ and Wakabayashi et $\mathrm{al}^{22}$ observed that the higher the degree of the polynomial, the more precise the graphic description of the dental arch. In previous studies of lingual arch form, authors have used $9^{\text {th }}$ degree polynomial to best describe the arch form as it had shown the lowest 
Table 4 Cluster Properties

\begin{tabular}{|c|c|c|c|c|}
\hline & \multicolumn{3}{|l|}{ Cluster } & \multirow[b]{2}{*}{$\begin{array}{l}\text { p-value } \\
\text { (Cluster I and 2) }\end{array}$} \\
\hline & $\begin{array}{l}\text { I } \\
(\text { Mean } \pm \text { SD) }\end{array}$ & $\begin{array}{l}2 \\
(\text { Mean } \pm S D)\end{array}$ & $\begin{array}{l}\text { Combined } \\
(\text { Mean } \pm \text { SD) }\end{array}$ & \\
\hline Inter-canine width (mm) & $21.76 \pm 1.17$ & $23.38 \pm 0.88$ & $22.39 \pm 1.32$ & $0.00 *$ \\
\hline Inter-molar width $(\mathrm{mm})$ & $32.44 \pm 1.25$ & $36.34 \pm 1.36$ & $33.98 \pm 2.32$ & $0.00 *$ \\
\hline Inter-2nd molar width $(\mathrm{mm})$ & $38.94 \pm|.7|$ & $43.05 \pm 1.38$ & $40.56 \pm 2.57$ & $0.00 *$ \\
\hline Canine depth (mm) & $4.46 \pm 1.06$ & $4.61 \pm .87$ & $4.5 \pm .98$ & 0.74 \\
\hline First molar depth $(\mathrm{mm})$ & $25.26 \pm 1.65$ & $25.56 \pm .98$ & $25.38 \pm 1.41$ & 0.74 \\
\hline Second molar depth $(\mathrm{mm})$ & $34.37 \pm 1.93$ & $35.36 \pm 1.32$ & $34.76 \pm 1.76$ & 0.2 \\
\hline Canine width/depth & $5.16 \pm 1.34$ & $5.24 \pm 1.00$ & $5.19 \pm 1.20$ & 0.76 \\
\hline First molar width/depth & $1.28 \pm .096$ & $1.42 \pm .093$ & $1.34 \pm .11$ & $0.00 *$ \\
\hline Second molar width/depth & $1.13 \pm .063$ & $1.21 \pm .072$ & $1.16 \pm .077$ & $0.01 *$ \\
\hline
\end{tabular}

Notes: $\mathrm{P} \leq 0.05$, *statistically significant.

standard error values. ${ }^{4,6}$ The criteria for selection of polynomial function was the standard error. The lower the standard error, the better was the fit. In our study, the lowest standard error for the mandibular arch was observed with a $10^{\text {th }}$ degree polynomial. Hence, this polynomial function was used to describe the arch form.

Only a few population-specific studies regarding classification of lingual arch form have been published. Lombardo et $\mathrm{al}^{4}$ described three arch forms, namely large, medium and small in the European population. In another similar study, Park et $\mathrm{al}^{6}$ used three-dimensional virtual models for digitizing the reference points and described four clusters in the Korean population, namely wide, narrow, tapering and ovoid types. Kairalla et $\mathrm{al}^{5}$ used linear measurement instead of polynomial equations to describe arch forms in Caucasian Brazilians. They concluded that the lingual arch form was parabolic in
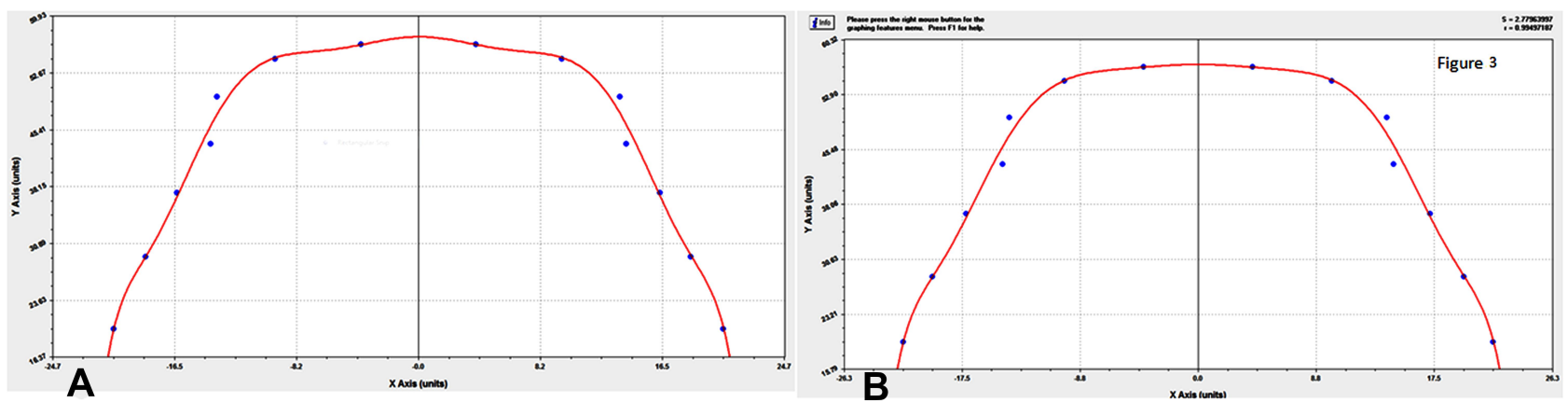

Figure 3 Template of maxillary lingual arch form. (A) Cluster I. (B) Cluster 2.
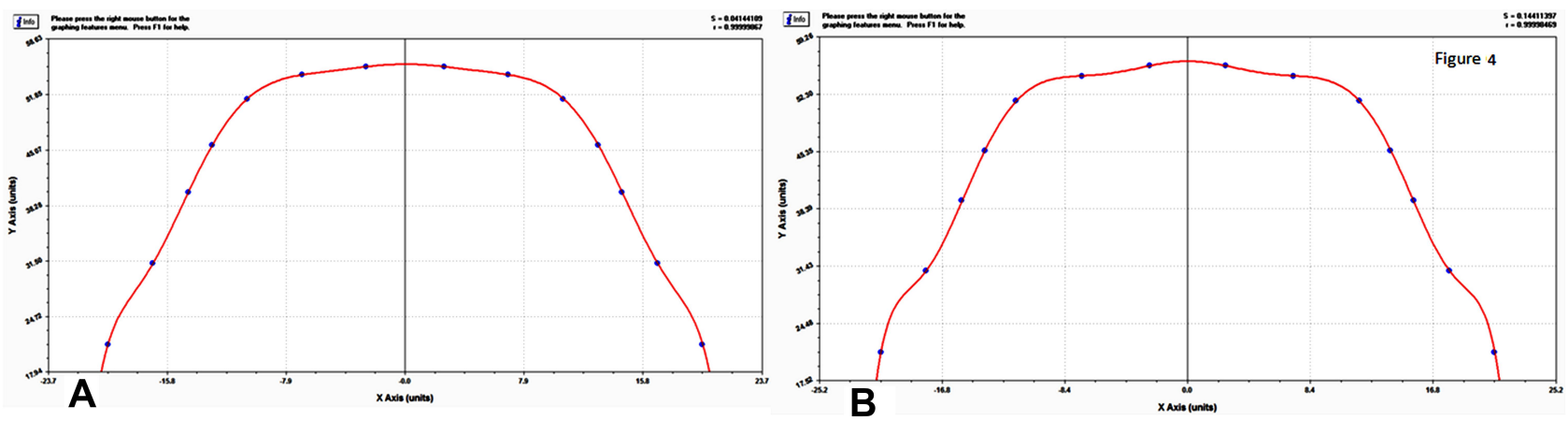

Figure 4 Template of mandibular lingual arch form. (A) Cluster I. (B) Cluster 2. 
shape and slightly flattened in the anterior portion. The dimensions of cluster 1 of our study closely resemble that of cluster 3 (narrow) as described by Park et al, ${ }^{6}$ and the narrow arch form as described by Lombardo et al. ${ }^{4}$ The cluster 2 of our study sample has relatively narrow inter-canine and broad intermolar widths which resemble cluster 1 (tapering) of the Korean study sample. ${ }^{6}$ In our study, only two clusters were identified which may be because of the study's small sample size. Till past few years, dental treatment was available only in major cities of Nepal and only limited sections of the population had the awareness and financial means to seek dental care. $^{23,24}$ Hence, it is rare to find adults/young adults with dental arches with a full complement of teeth and with a normal occlusion. Because of this limitation, the present study should be considered a pilot study and further investigations with larger sample sizes are recommended.

\section{Conclusions}

Two arch forms for the maxillary and mandibular lingual arches were depicted which could serve as templates for the fabrication of lingual archwires in Nepalese orthodontic patients. There was no statistically significant difference in the arch size measurements between Nepalese males and female dental students.

\section{Data Sharing Statement}

The datasets used and/or analyzed during the current study are available from the corresponding author on reasonable request.

\section{Ethics Approval and Consent to Participate}

Ethical clearance was has been obtained from the Institute review committee of the Kathmandu University School of Medical Sciences (Approval no: 91/20).

\section{Consent for Publication}

Not applicable.

\section{Acknowledgments}

The authors will like to thank Dr John Kanyusik, Associate professor, Department of Orthodontics, University of Minnesota for editing the manuscript.

\section{Funding}

There is no funding to report.

\section{Disclosure}

The authors declare that they have no competing interests.

\section{References}

1. Raberin M, Laumon B, Martin JL, Brunner F. Dimensions and form of dental arches in subjects with normal occlusions. Am J Orthod Dentofacial Orthop. 1993;104:67-72. doi:10.1016/0889-5406(93) 70029-N

2. Strang RHW. Factors of influence in producing a stable result in the treatment of malocclusion. Am J Orthod Oral Surg. 1946;32:313332. doi:10.1016/0096-6347(46)90123-8

3. Lee S, Lee S, Lim J, Park H, Wheeler TT. Methods to classify dental arch forms. Am J Orthod Dentofacial Orthop. 2011;140:87-96. doi:10.1016/j.ajodo.2011.03.016

4. Lombardo L, Saba L, Scuzzo G, et al. A new concept of anatomic lingual arch form. Am J Orthod Dentofacial Orthop. 2010;138:260. e1-e13. doi:10.1016/j.ajodo.2010.04.022

5. Kairalla SA, Scuzzo G, Triviño T, Velasco L, Lombardo L, Paranhos LR. Determining shapes and dimensions of dental arches for the use of straight-wire arches in lingual technique. Dental Press J Orthod. 2014;19(5):116-122. doi:10.1590/2176-9451.19.5.116-122.oar

6. Park KH, Bayome M, Park JH, Lee JW, Baek SH, Kook YA. New classification of lingual arch form in normal occlusion using three dimensional virtual models. Korean J Orthod. 2015;45:74-81. doi:10.4041/kjod.2015.45.2.74

7. Auluck A. Lingual orthodontic treatment: what is the current evidence base? J Orthod. 2013;40(Sup1):s27-33. doi:10.1179/14653 13313Y.0000000073

8. George RD, Hirani S. Fully-customized lingual appliances: how lingual orthodontics became a viable treatment option. J Orthod. 2013;40(Sup1):s8-13. doi:10.1179/1465313313Y.0000000058

9. Tarazona-Alvarez B, Lucas-Dominguez R, Paredes-Gallardo V, Alonso-Arroyo A, Vidal-Infer A. A bibliometric analysis of scientific production in the field of lingual orthodontics. Head Face Med. 2019; $15: 1$.

10. Fillion D. Clinical advantages of the Orapix-straight wire lingual technique. Int Orthod. 2010;8(2):125-151.

11. Takemoto K, Scuzzo G, Lombardo LU, Takemoto YU. Lingual straight wire method. Int Orthod. 2009;7:335-353.

12. Lavelle CL, Foster TD, Flinn RM. Dental arches in various ethnic groups. Angle Orthod. 1971;41(4):293-299.

13. Mishra RK, Devagiri V. Comparison and testing the reliability of two non-radiographic techniques of mixed dentition space analysis in Nepalese population. JCMS Nepal. 2017;13(4):410-415.

14. Definition of cartesian coordinate system | Dictionary.com [Internet]. www.dictionary.com; 2020. Available from: https://www.dictionary. com/browse/cartesian-coordinate-system. Accessed June 5, 2020.

15. Triviño T, Siqueira DF, Scanavini MA. A new concept of mandibular dental arch forms with normal occlusion. Am $J$ Orthod Dentofacial Orthop. 2008;133:10.e15-22.

16. Dahlberg G. Statistical Methods for Medical and Biological Students. London: George Allen and Unwin; 1940:pp. 122-132.

17. IBM knowledge center [internet]. Ibm.com; 2020. Available from: https://www.ibm.com/support/knowledgecenter/en/SSLVMB_24.0.0/ spss/base/idh_twostep_main.html. Accessed June 5, 2020.

18. Kageyama T, Domínguez-Rodríguez GC, Vigorito JW, Deguchi T. A morphological study of the relationship between arch dimensions and craniofacial structures in adolescents with Class II Division 1 malocclusions and various facial types. Am J OrthodDentofacialOrthop. 2006;129::368-375. doi:10.1016/j.ajodo.2005.12.005

19. Lu KH. An orthogonal analysis of the form, symmetry, and asymmetry of the dental arch. Arch Oral Biol. 1966;11:1057-1069. doi:10.1016/0003-9969(66)90164-6 
20. Pepe SH. Polynomial and catenary curve fits to human dental arches. $J$ Dent Res. 1975;54(6):1124-1132. doi:10.1177/00220345750540060501

21. Ferrario VF, Sforza C, Miani AJ, Tartaglia G. Mathematical definition of the shape of dental arches in human permanent healthy dentitions. EurOrthod Soc. 1994;16:287-294.

22. Wakabayashi K, Sohmura T, Takahashi J, et al. Development of the computerized dental cast form analyzing system-three dimensional diagnosis of dental arch form and the investigation of measuring condition. Dent Mater J. 1997;16:180-190. doi:10.4012/dmj.16.180
23. Yee R, Mishra P. Nepal national oral pathfinder survey 2004. J Nepal Dent Assoc. 2005;7(1):64-68.

24. Thapa P, Aryal K, Mehata S, et al. Oral hygiene practices and their socio-demographic correlates among Nepalese adult: evidence from non communicable diseases risk factors STEPS survey Nepal 2013. BMC Oral Health. 2016;16:1. doi:10.1186/s12903016-0294-9

Clinical, Cosmetic and Investigational Dentistry

\section{Publish your work in this journal}

Clinical, Cosmetic and Investigational Dentistry is an international, peer-reviewed, open access, online journal focusing on the latest clinical and experimental research in dentistry with specific emphasis on cosmetic interventions. Innovative developments in dental materials, techniques and devices that improve outcomes and patient satisfaction and preference will be highlighted. The manuscript management system is completely online and includes a very quick and fair peer-review system, which is all easy to use. Visit http://www.dovepress.com/testimonials.php to read real quotes from published authors. 